\title{
Surgery on the Trabecular Meshwork: Histopathological Evidence
}

\author{
${ }^{1}$ Shibal Bhartiya, ${ }^{2}$ Parul Ichhpujani, ${ }^{3}$ Tarek Shaarawy
}

\begin{abstract}
Juxtacanalicular (JXT) trabecular meshwork and endothelial lining of Schlemm's canal have been cited as the loci of aqueous outflow resistance, both in a normal as well as a glaucomatous eye. In this review, we attempt to understand the currently available surgical modalities in light of the available histopathological evidence, regarding localization of outflow resistance.
\end{abstract}

Keywords: Aqueous outflow and resistance, Histopathological basis of glaucoma surgery, Outflow facility, Trabecular meshwork.

How to cite this article: Bhartiya S, Ichhpujani P, ShaarawyT. Surgery on the Trabecular Meshwork: Histopathological Evidence. J Curr Glaucoma Pract 2015;9(2):51-61.

\section{Source of support: Nil}

Conflict of interest: None

\section{INTRODUCTION}

In primary open angle glaucoma (POAG), the primary cause of increase to outflow resistance is located within the trabecular meshwork (TM), and logically may be eliminated by incising the same. ${ }^{1-10}$ In view of current knowledge, microsurgical dissection of the TM has again become the focus of attention among glaucoma surgeons. ${ }^{7-8}$ Even though there has been little addition in the existing knowledge about the classic procedures in terms of mechanism of action, there has been a trend toward more physiological approach, with regard to resistance to aqueous outflow in newer surgical approaches. ${ }^{9}$ This review is an attempt to analyze the currently available surgical modalities on the basis of available histopathological evidence regarding localization of outflow resistance.

\footnotetext{
${ }^{1}$ Senior Consultant, ${ }^{2}$ Associate Professor, ${ }^{3} \mathrm{Head}$

${ }^{1}$ Glaucoma Facility, Fortis Memorial Research Institute, Gurgaon Haryana, India

${ }^{2}$ Department of Ophthalmology, Glaucoma Facility, Government Medical College and Hospital, Chandigarh, India

${ }^{3}$ Glaucoma Sector, Geneva University Hospital, Rue GabriellePerret-Gentil 4, 1205 Geneva, Switzerland
}

Corresponding Author: Tarek Shaarawy, Head, Avenue de France 15, CH-1004 Lausanne, Switzerland, Phone: +41 21626 8224, Fax: +41 21626 8246, e-mail: tarek.shaarawy@hcuge.ch

\section{Functional Anatomy}

The trabecular meshwork bridges the scleral sulcus, converting it into a circumferential channel, called the Schlemm's canal (SC). The TM is a triangular, porous structure, in cross-section, that consists of connective tissue surrounded by endothelium. It is divided into three components: uveal meshwork, corneoscleral meshwork and juxtacanalicular (JXT) meshwork. ${ }^{11,12}$

The uveal meshwork forms the lateral border of the anterior chamber, extending from the iris root and ciliary body to the peripheral cornea. It consists of bands of connective tissue, with irregular openings that measure between 25 and 75 microns.

The corneoscleral meshwork extends from the sclera spur to the anterior wall of the scleral sulcus. It is the most extensive portion of the TM, and is composed of perforated sheets that become progressively smaller nearing SC.

The outermost part of the TM, composed of a layer of connective tissue lined on either side by endothelium, is called the JXT meshwork. The central connective tissue layer has variable thickness and is non-fenestrated, and the outer endothelial layer comprises the inner wall of SC. ${ }^{11-17}$

The outermost JXT or cribriform region has no collagenous beams, rather several cell layers immersed in a loose web of extracellular matrix (ECM) fibrils, with small tortuous aqueous pathways that appear as empty space under electron microscopy. The ECM contains basement membrane material, proteoglycans, and glycosaminoglycans, providing significant outflow resistance. ${ }^{18}$

The SC is comprised of endothelial cells surrounded by connective tissue, like a vein. This has the highest hydraulic conductivity of any endothelium in the body. It constitutes a leaky lining probably because of the numerous micron-sized transcellular pores in the endothelium and the associated giant vacuoles. ${ }^{19,20-25}$

Schlemm's canal, under normal conditions, is not a site of considerable outflow resistance. However, with an increase in intraocular pressure (IOP), the TM expands into the lumen of the canal, causing its concomitant narrowing, with a significant increase in outflow resistance. ${ }^{25}$ Collagenous septae between the inner and outer walls, especially near the collector channels, are probably a safeguard against collapse of the canal and occlusion of collector channels with an increase in IOP. ${ }^{25,26}$ 
The SC possesses internal collector channels and is connected to episcleral and conjunctival veins through the external collector channels, the intrascleral venous plexus, the deep scleral plexus and the aqueous veins. ${ }^{27,28}$

\section{Aqueous Outflow and Resistance}

Almost $70 \%$ aqueous humor outflow is accounted for by the 'conventional' outflow pathway via the anterior chamber to the trabecular meshwork, SC, and collector channels; entering the systemic venous circulation in the episcleral veins. The remaining $30 \%$ may leave the 'eye through the uveoscleral, or unconventional' outflow pathways; which is a passive fluid movement down a pressure gradient. ${ }^{19,29-31}$

In uveoscleral outflow, aqueous humor enters the ciliary muscle and exits through the supraciliary space, across the anterior or posterior sclera through the emissarial canals around the vortex veins, or into the choroidal vessels. ${ }^{32,33}$

Uveoscleral outflow may be considered analogous to lymphatic drainage of tissue fluid, as the fluid may mix with tissue fluid from the ciliary muscle, ciliary processes and choroid; and is drawn osmotically into the veins. ${ }^{34} \mathrm{In}$ non-human primates, 40 to $50 \%$ of aqueous humor exits the eye by the uveoscleral route. In human eyes, most data have been collected by indirect calculations, using the expanded Goldmann equation $[\mathrm{F}=(\mathrm{Pi}-\mathrm{Pe}) \times \mathrm{C}+\mathrm{U}$; where, ' $\mathrm{F}$ ' is the rate of aqueous humor formation, ' $\mathrm{Pi}^{\prime}$ is the intraocular pressure, ' $\mathrm{Pe}^{\prime}$ is the episcleral venous pressure, ' $C$ ' is the tonographic facility of outflow, and ' $U$ ' is the pressure insensitive parameter to symbolize uveoscleral outflow], suggesting a similar fraction, at least in eyes, from younger individuals. ${ }^{35,36}$

Ciliary muscle contraction greatly affects uveoscleral outflow, and prostaglandin $\mathrm{F}_{2 \alpha}$ greatly increases uveoscleral outflow by decreasing the flow resistance of the interstitial spaces in the ciliary muscle. ${ }^{37,38}$

In eyes treated with atropine, uveoscleral flow accounts for 4 to $27 \%$ of the total outflow, but with pilocarpine it was only 0 to $3 \% .{ }^{39}$ An age-dependent reduction in uveoscleral flow in human eyes may explain the initial difference seen between non-human primate and human eyes. ${ }^{11,40}$

\section{Localization of Resistance}

In humans, $75 \%$ of the resistance to the aqueous humor outflow is localized to the TM, and $25 \%$ beyond SC, in the outer wall of SC or tissue surrounding it. $2,9,11,41-48$ The major site of resistance within the TM structure has not yet been well characterized, but most investigators agree that almost two thirds (up to $75 \%$ ) is localized in the JXT portion. ${ }^{2,9,42,43,46,49}$ There have been reports that the incision of the uveal and proximal corneoscleral layers of the TM did not affect outflow resistance, while a deeper incision through the entire meshwork and into SC, eliminated $75 \%$ of the normal outflow resistance. ${ }^{2,9}$

The major mechanisms through which resistance across the conventional outflow pathway may be regulated are:

- Transcellular route through vacuoles in the inner wall endothelial cells of SC.50-54

- Paracellular route passing between SC inner wall endothelial cells. ${ }^{54-57}$

- Turnover of extracellular matrix in the JXT region. ${ }^{54,58-64}$ It is important to note that aqueous can only reach either transcellular or paracellular pathways after traversing the JXT region of TM. ${ }^{54}$

Outflow resistance within the ciliary body (CB) is postulated to be regulated through ECM turnover in $\mathrm{CB}$ stroma and sclera, as well as by ciliary body smooth muscle cell tone, although the latter is controversial. . $^{2,54,65-71}$ Thus, both restructuring and turnover of ECM regulate outflow resistance in both conventional and uveoscleral pathways, through unknown molecular mechanisms. The ciliary muscle moves in an anterior and inward direction, resulting in spreading of the TM and dilation of SC during its contraction, thus decreasing outflow resistance. The opposite occurs during relaxation with a consequent increase in outflow resistance. ${ }^{11,72}$ Voluntary accommodation, electrical stimulation of the trigeminal nerve and local or systemic administration of cholinergic agents have been shown to decrease outflow resistance in animal models. ${ }^{73-77}$

\section{Aqueous Outflow Resistance and Glaucoma}

The outflow system responds biomechanically to the IOP, with IOP increase resulting in tissue and cellular deformation at the level of the SC endothelium. These pressure and shear stress-mediated signals initiate a highly complex interactive network of cellular, molecular and genetic changes, inducing both rapid responses and slow adaptive changes that regulate pressure and flow resulting in long-term homeostasis. ${ }^{11,78-80}$

A failure of this homeostatic mechanism results in chronic IOP increase, and the consequent characteristic optic neuropathy called 'glaucoma'. The increased IOP found in glaucoma is caused by an increase in aqueous outflow resistance within the drainage pathways and not by excess secretion of aqueous humor., ${ }^{9,201}$

Alterations in the trabeculum are presumed to lead to increased aqueous humor outflow resistance and elevated IOP in patients with POAG. Loss of trabecular cells is presumed to cause the structural alterations in the trabeculum. These changes are trabecular thickening, 
fusion of trabecular beams and accumulation of extracellular material in the endothelial meshwork, as well as a decrease in trabecular meshwork cellularity. ${ }^{82-89}$

There are several hypotheses pertaining to decreased trabecular cellularity in glaucoma. ${ }^{88-99}$ Grierson's hypothesis of migration of trabecular cells from the trabeculae to the endothelial meshwork in early POAG can explain the 'activated' and enlarged trabecular cells seen in the endothelium meshwork. ${ }^{90}$

Supranormal phagocytic activity of trabecular cells may be responsible for cell death, ${ }^{94}$ as well the detachment of cells from the meshwork and migration toward the SC. ${ }^{94-96}$ Mechanical stress resulting from elevated IOP or through trabecular hypoperfusion may also be contributory factors for this loss of trabecular cellularity. ${ }^{90,92}$

The ECM thickness beneath the inner wall of SC and in the JXT meshwork has been found to be higher in glaucomatous eyes than age-matched healthy controls. ${ }^{11,97,98}$ Modifications of the trabecular matrix with plaque like trabecular thickening and fusion, accumulation of ECM in the endothelial meshwork, atypical collagen and abundance of long spacing have also been reported. ${ }^{89,97,100-103}$ An impairment of the endothelial wall of SC in areas of modified cribriform extracellular matrix has also been seen. ${ }^{92,100}$

Biochemical analyses of TM specimens and aqueous humor proteins have reported a variety of differences between normal and glaucomatous eyes at the molecular level. Levels of TGF-beta2, VEGF, endothelin, PAI, and soluble CD44 are known to be elevated in the aqueous humor of POAG as compared to normal aqueous humor. The ECM is reported to have less hyaluronic acid and more chondroitin sulfate.

These molecules may be the reason for the changes seen in the TM, but it is essential to keep in mind that these may be attributable to the chronic use of glaucoma medications, the effect of which on the molecular composition of TM is yet to be ascertained. ${ }^{104-112}$

The collapse of SC may be considered contributory to the increase in outflow resistance. However, outflow resistance at high IOPs has not been found to be as high as those found in glaucoma. In normal eyes, facility of outflow decreases from $0.40 \mu \mathrm{L} / \mathrm{min} / \mathrm{mm} \mathrm{Hg}$ at $10 \mathrm{~mm}$ $\mathrm{Hg}$ to $0.28 \mu \mathrm{L} / \mathrm{min} / \mathrm{mm} \mathrm{Hg}$ at $50 \mathrm{~mm} \mathrm{Hg}$. In comparison to this, the facility of eyes with POAG is usually less than $0.13 .^{19,26,113}$

\section{Bypassing the Resistance}

Most current surgical modalities attempt to lower the IOP by increasing aqueous outflow, but not for cycloablative procedures that endeavor to decrease aqueous humor production.
Surgeries, such as trabeculectomy, glaucoma drainage implants and shunts (which penetrate the TM and cannulate SC or create a path through the scleral wall), all attempt to bypass outflow resistance by shunting aqueous humor away from the TM. Canaloplasty and newer shunts which create a mini-cyclodialysis cleft increase the uveoscleral outflow by opening existing aqueous drainage pathways or creating new pathways.

Deep sclerectomy unroofs the SC, removing its inner wall as well the JXT meshwork, removing the site of maximal outflow resistance.

\section{Surgeries that Increase Aqueous Outflow}

1. Surgeries that bypass conventional aqueous outflow pathway:

- Trabeculectomy

- Non-penetrating deep sclerectomy

- Glaucoma drainage devices

- Viscocanalostomy, Canaloplasty

- Ab interno trabeculotomy or Trabectome surgery

- Trabeculotomy (limited to congenital glaucoma)

- Goniotomy (limited to congenital glaucoma)

2. Surgeries that increase the uveoscleral outflow:

- Suprachoridal Gold SOLX shunt

- CyPass

- Express shunt

- I stent

\section{Surgeries that Decrease Aqueous Production}

- Contact (transcleral) cycloablation

- Cyclocryotherapy

- Diode

- Nd:YAG

- Noncontact cycloablation

- Nd:YAG

- Diode

- Transpupillary argon green cyclophotocoagulation

- Endolaser ablation

- Diode

- Argon

This review focuses on the surgeries on the trabecular meshwork, all of which work on the principle of increasing aqueous outflow.

\section{Surgeries that Increase Aqueous Outflow}

The era of modern surgery for glaucoma was heralded by the introduction of the concept of trabeculotomy by Smith, which was developed further by Harms and Dannheim. ${ }^{114,115}$ Krasnov introduced sinusotomy when trabecular function appeared adequate. ${ }^{116}$ Sinusotomy and trabeculotomy were combined to produce a filtering 
bleb with an intact anterior chamber. ${ }^{117}$ In 1968, Cairns introduced the current gold standard of glaucoma surgery, the 'trabeculectomy'.118

\section{Mechanism of Action}

Trabeculectomy: Trabeculectomy essentially functions as a guarded full thickness sclerectomy, although Cairns originally postulated that removal of TM would allow free flow of fluid into the open lumen of the SC, bypassing trabecular resistance. ${ }^{118}$

A fistula between the anterior chamber and the subconjunctival space directs the aqueous to the subconjunctival space, and is thereafter directly absorbed into the sclera and episcleral vasculature to enter the orbital circulation, bypassing both the conventional and uveoscleral pathways. ${ }^{119}$ A new pathway of outflow is thus created through the sclera and into a tissue not normally exposed to eye fluid pressure, fluid shear or tissue swelling.

Despite modulation of the subconjunctival space into a porous matrix, the procedure is not a physiological bypass, and remains dependent on the size of the ostium, tension in the sclera flap, as well as wound healing and its modulation.

A decrease in the hydraulic conductivity of the bleb capsule leads to a rise in fluid pressure within the bleb, changing its mechanical and biochemical environment leading to progressive scarring and consequent bleb failure. ${ }^{119}$

McEwen postulated that a single patent hole of $12 \mu \mathrm{m}$ is by itself sufficiently large to provide a normal facility of outflow. ${ }^{120}$ A small sclerostomy $(0.5 \mathrm{~mm})$ has been found to be adequate, minimize astigmatism and the chance of limbal aqueous flow, and may maximize the chance of controlling outflow. ${ }^{121}$

Experiments have shown that the simple aqueous outflow of protruding human eyes increases 26 folds, from $0.24 \pm 0.08 \mathrm{ml} / \mathrm{min} / \mathrm{mm} \mathrm{Hg}$ to $6.33 \pm 6.67 \mathrm{ml} / \mathrm{min} /$ $\mathrm{mm} \mathrm{Hg}$ after external trabeculectomy. This may be explained by the fact that during external trabeculectomy, the diaphragm through the aqueous outflow consists only of the uveal meshwork and the largest inner part of the corneoscleral TM. ${ }^{119}$

The mean outflow facility after non-penetrating glaucoma surgeries (NPGS) $(1.584 \pm 0.217 \mu \mathrm{l} / \mathrm{min} / \mathrm{mm} \mathrm{Hg})$ is relatively lower than reported mean outflow facility after trabeculectomy $(2.96 \pm 0.60 \mu \mathrm{l} / \mathrm{min} / \mathrm{mm} \mathrm{Hg})$, which possibly accounts for the gradual decrease in IOP after NPGS, opposed to the sudden drop in pressure after penetration as in the case of trabeculectomy. ${ }^{122,123}$

Schie's procedure or full thickness filtration surgeries: Full thickness procedures like thermal sclerostomy, anterior or posterior lip sclerectomy and Elliots' trephination lack a guard over the sclerostomy except the tenons- conjunctival complex, with a limbus-based conjunctival flap. The tamponading effect of the partial thickness sclera flap is lacking and the aqueous egress is unimpeded.

They are therefore prone to problems relating to hypotony and over filtration, cataract formation due to shallow ACs as well as late infections, and hence are no longer performed.

Shunts/Tubes: All commercially available conventional shunts consist of a tube designed to shunt aqueous from the anterior chamber to a distal plate in the posterior subconjunctival space, from where aqueous is directly absorbed into the sclera and episcleral vasculature to enter the orbital circulation, bypassing both the conventional and uveoscleral pathways. The primary tube-plate junction includes a rim, through which the tube empties onto the explant plate surface to avoid closure of the tube orifice following eventual encapsulation of the device by fibrosis. The shunting to the metabolically less active posterior subconjunctival filtration has implications in terms of potential advantages, such as less subconjunctival fibrosis, larger subconjunctival reservoir and less bleb dysthesias and failure rates.

Examples of aqueous shunts include the-Ahmed (New World Medical Inc, Rancho Cucamonga, CA), Baerveldt (Advanced Medical Optics Inc, Santa Ana, CA), Krupin (Eagle Vision) and Molteno (Molteno Ophthalmic Limited, Dunedin, New Zealand) shunts. These devices differ depending on explant surface areas, shape, plate thickness, the presence or absence of a valve and details of surgical installation.

Incorporation of a valve or flow restrictor in aqueous shunts, in theory, should reduce the risk of immediate postoperative hypotony common to nonvalved devices when placed without temporary tube ligation. ${ }^{124-126}$

Non-penetrating glaucoma surgeries: Non-penetrating surgeries are based on the premise that aqueous egress occurs at the level of SC and its efferents, and that the selective removal of the external part the trabecular meshwork that is mainly involved in aqueous outflow resistance (inner wall of SC and the adjacent trabecular meshwork), while leaving intact the innermost trabecular meshwork layers. ${ }^{11,127-130}$ Thus, the outflow facility is increased, while retaining a degree of residual outflow resistance by leaving a membrane between the anterior chamber and the scleral dissection. This membrane is formed by the anterior and posterior trabecular meshwork, the internal endothelium of Schlemm's canal and Descemet's membrane in deep sclerectomy or viscocanalostomy. ${ }^{119}$

The removal of the JXT trabecular meshwork and the inner wall of SC to decrease aqueous outflow resistance was proposed by Zimmerman et al. ${ }^{128}$ This procedure 
was called 'ab-externo trabeculectomy', and performed under a scleral flap. Drainage was found to occur at the level of the posterior trabeculum, with an increase in the outflow facility following removal of the inner wall of SC and the JXT meshwork (from $0.2 \pm 0.6$ to $2.03 \pm 1.43 \mu \mathrm{l}$ / min per $\mathrm{mm} \mathrm{Hg})^{127-131}$

Deep sclerectomy consisted of removal of corneal stroma behind the anterior trabeculum and the Descemet's membrane under a scleral flap, so that aqueous humor drainage occurred at the level of the anterior trabeculum and Descemet's membrane. ${ }^{132}$ This was reported to result in a greatly increased outflow facility (from $0.19 \pm 0.03$ to $24.5 \pm 12.6 \mu \mathrm{l} / \mathrm{min}$ per $\mathrm{mm} \mathrm{Hg})^{133}$

Modern day non-penetrating deep sclerectomy combines both of these procedures, and its complete nomenclature therefore is 'deep sclerectomy with external trabeculectomy'. ${ }^{\prime 27,132-141}$

Viscocanalostomy is known to work on the same principle, but involves the additional injection of viscoelastic substance in the SC ostia. ${ }^{143}$ The procedure requires careful scraping of the bed of SC with a forceps, or trabecular aspiration. This leads to the removal of a homogenous external trabecular membrane in one coherent plane that allows aqueous humor to egress through the remaining inner trabecular layers. ${ }^{127-144}$

\section{Pathways of Aqueous Drainage in NPGS}

\section{Deroofing Schlemm's Canal}

In external trabeculectomy, the removal of the inner wall of SC and the adjacent trabecular layers are designed to remove the part of the TM that is involved in the main aqueous outflow resistance. Removal of the outer wall causes damage to the inner wall of the canal as the septae, which bridge the inner and outer walls, are pulled away during the unroofing procedure. Such damage to the inner wall and adjacent JXT region effectively removes these regions and allows aqueous humor access to the canal. ${ }^{19,20,129,145}$ Other contributing factors include thinning of the trabecular meshwork and vaulting of residual trabecular meshwork vaults towards the intrascleral cavity, leading to a widening of the cribriform interspace (similar to laser trabeculoplasty). ${ }^{146}$

Ex-vivo confocal microscopy has revealed that this external trabecular membrane involves not only the inner wall of SC and the JXT meshwork, but also a part of the corneoscleral layers. ${ }^{138}$ The drainage thus occurs at the level of the posterior trabeculum through the innermost layers of the TM, which are left intact and aqueous humor reaches the scleral lake $\mathrm{e}^{19,20,128}$ and then the subconjunctival spaces as demonstrated by the presence of filtering bleb (observed in most of the cases of deep sclerectomy with external trabeculectomy; usually more diffuse or smaller than after trabeculectomy. ${ }^{127}$

\section{Creation of Descemet's Window}

Excising a deep layer of sclera and exposing Descemet's membrane may create a route for aqueous drainage that bypasses the meshwork, through the intact trabeculodescemetic membrane namely at the level of the anterior trabeculum, from where it reaches the scleral lake. ${ }^{19,20,128,132}$ Descemet's membrane, however, is not permeable enough to relieve the elevated pressure of glaucoma. ${ }^{23,24} \mathrm{~A}$ window of exposed Descemet's membrane approximately $21 \times 21 \mathrm{~mm}$ would be required to lower IOP to the low teens. Following its partial removal during the procedure, its permeability increases. Also, the permeability of the trabeculo Descemet's membrane probably also increases due to properties of the meshwork remaining after the unroofing of SC.

An index of relative impermeability of Descemet's membrane is supported by $41 \%$ goniopuncture rate after deep sclerectomy. ${ }^{5}$

\section{Injection of Viscoelastic Material}

In viscocanalostomy, injection of viscoelastic material into the ends of SC is designed to enhance aqueous egress through the cut ends of SC and through previously non-functional areas of SC, and then aqueous collector channels, thereby lowering IOP. ${ }^{1}$ The viscoelastic is resorbed in 4 to 5 days, which is not long enough to prevent healing of the cut ends of the canal. A more likely explanation is that expansion of the canal ruptures both the inner and outer endothelial walls of the canal, extending into the juxtacanalicular connective tissue and some of the meshwork. ${ }^{22}$ Therefore, both viscocanalostomy and deep sclerectomy function as 'gentle' trabeculotomies, allowing aqueous to bypass the site of abnormal outflow resistance, the JXT; through inadvertent ruptures in the JXT and the inner wall of the canal and also through the unroofed outer wall. If the ruptured regions of the JXT and canal heal with time, surgery may fail in eyes that did not develop filtration blebs.

\section{Alternate Pathways}

Injection of viscoelastic in SC also results in focal disruptions of the inner wall endothelium of SC and disorganization of the JXT zone, resulting in direct communication of the JXT extracellular spaces with the lumen of SC. This may, therefore, initially enhance conventional aqueous outflow, accounting for approximately 30\% increase in 
outflow facility in non-human primates. ${ }^{147}$ Disruption of the posterior wall of the SC may also provide direct communication between its lumen and the tissues of the $\mathrm{CB}$, thereby enhancing uveoscleral outflow. ${ }^{148}$

The viscoelastic material also has anti-inflammatory properties and may inhibit cellular migration, phagocytosis and cytokine production; and thus may interfere with wound healing. ${ }^{81}$

After aqueous humor passage through the trabeculoDescemet's membrane, four hypothetical mechanisms of aqueous resorption may occur-a subconjunctival filtering bleb, an intrascleral filtering bleb, a suprachoroidal filtration and an episcleral vein outflow via Schlemm's canal. $^{149,150}$

\section{Canaloplasty}

This is a new surgical procedure in which a tensioning suture is placed within the SC when possible, to apply inward directed tension on the TM, in addition to viscodilation. Potentially, the suture tension may increase TM permeability, similar to the action of pilocarpine, as well as help maintain a patent canal lumen, similar to the intraocular tensioning suture. ${ }^{12-14}$

\section{Anterior Chamber Drainage Angle Surgery: Trabeculotomy, Trabeculectomy ab interno}

Reported success of trabeculotomy and goniotomy has ranged between 68 and 100\%, in infants and young children with congenital glaucoma. Poor long-term success in adults has been presumably due to the formation of anterior synechiae in the postoperative phase. Ab interno trabeculectomy using the Trabectome ${ }^{\mathrm{TM}}$ (NeoMedix, Tustin, CA) aims to selectively remove the $\mathrm{TM}$ and inner wall of SC, while leaving the rest of the outflow system (outer wall of SC, collector channels, and aqueous veins) relatively intact, and attempts to avoid anterior synechiae formation or other forms of wound healing with resultant closure of the cleft. ${ }^{151-153}$

A strip of TM and inner wall of SC spanning 80 to $100^{\circ}$ is ablated and removed under direct gonioscopic visualization. Intraoperative reflux of blood through the resulting cleft is desirable in this procedure and confirms appropriate ab interno 'unroofing' of Schlemm's canal. The simultaneous aspiration of tissue debris, theoretically, reduces the inflammatory stimuli and opportunity for scarring among shards of incised or ruptured tissues remaining after traditional goniotomy or trabeculotomy.

Importantly, it does not preclude standard surgery subsequently, as the conjunctiva is not traumatized; however, the IOP lowering effect has been less as compared to conventional filtration surgeries.

\section{Transtrabecular Shunt: iStent Trabecular Micro-Bypass Device}

The iStent trabecular microbypass (Glaukos, Laguna Hills, Calif.) provides a channel for direct transtrabecular aqueous outflow from anterior chamber to collector channels. It is self-retaining and constructed of implant grade titanium Ti6AL4V and heparin coated implant, angled on one side of its arch shaped body, with an inlet of $80 \mathrm{~mm}$ internal diameter on the other side.

The iStent is placed via an ab externo approach under gonioscopic control into the SC. ${ }^{154,155}$ This microbypass stent sits in the canal itself, with a circumferential extension of $1 \mathrm{~mm}$ into the $36 \mathrm{~mm}$ long canal, with a snorkel in the anterior chamber through which the aqueous enters the SC.

Cultured autopsy eye perfusion experiments have shown that adding successive bypass shunts produces a step-wise increase in outflow. This in vitro experiment demonstrated a potential for achieving very low IOP with such devices, but is yet to be replicated in vivo. Reportedly, the first shunt has the most effect, dropping IOP from 21.4 \pm 3.8 to $12.4 \pm 4.2 \mathrm{~mm} \mathrm{Hg}$. Successive addition of up to four stents placed into SC produced step-wise reduction in system pressure (from $13.6 \pm 4.1$ to $10.0 \pm 4.3 \mathrm{~mm} \mathrm{Hg}$ ); while complete removal of the meshwork lowered IOP to $6.3 \pm 3.2 \mathrm{~mm} \mathrm{Hg}$. ${ }^{156}$

\section{EyePass Bi-Directional Glaucoma Implant}

The EyePass Glaucoma Implant (GMP Companies, Inc, Ft Lauderdale, FL) is a bidirectional shunt that diverts aqueous from the anterior chamber directly into Schlemm's canal. It consists of a dual $6.0 \mathrm{~mm}$ long silicone tube, bonded at one end for less than $1.0 \mathrm{~mm}$, creating a Y-shape. The inner diameter of the silicone tube is $125 \mu \mathrm{m}$ and the outer diameter is $250 \mu \mathrm{m}$, making the tube narrow enough to fit the lumen of the SC. The bidirectional shunt is easily identified after implantation as blood refluxes from Schlemm's canal into the lumen of the unit. Not much has been reported about this device yet as it is undergoing clinical trials.

\section{Suprachoroidal Shunt}

The solx gold shunt is an ab externo suprachoroidal translimbal shunt and works as a 'controlled' cyclodialysis, draining aqueous into the suprachoroidal space. The anterior end of this 24-karat gold device with dimensions of $5.2 \mathrm{~mm}$ length, $3.2 \mathrm{~mm}$ width and 44 to $68 \mathrm{~mm}$ thickness (XGS-5 and XGS-10, respectively) is placed into the anterior chamber over the sclera spur via a scleral incision and the posterior end positioned in the suprachoroidal space. It includes several channels through its body, besides those initially functioning that potentially can be 
successively opened after installation via a laser applied to windows in its anterior chamber component for in vivo postoperative adjustments in outflow, to compensate for possible decrease in outflow with time. The flow resistance is stated to be 0.65 to $1.3 \mathrm{~mm} \mathrm{Hg} / \mathrm{ml} / \mathrm{min}$. Aqueous flows both through the channels in the body of the shunt as well as around its body.

Mastropasqua et al used in vivo confocal microscopy to show that successful gold microshunt implantation significantly increased conjunctival microcysts density and surface at the site of the device insertion. ${ }^{157}$ These findings suggest that the enhancement of the aqueous filtration across the sclera may be one of the possible outflow pathways exploited by the shunt.

\section{EX-PRESS Glaucoma Filtration Device}

EX-PRESS Glaucoma Filtration Device ${ }^{\circledR}$ (Alcon, Fort Worth, Texas) is an implantable stainless steel 2 to $3 \mathrm{~mm}$ long and $0.4 \mathrm{~mm}$ diameter tube, which connects the anterior chamber to the intrascleral space. The 27 gauge shaft is designed to approximate the thickness of the human sclera, and has a spur on its underside to prevent extrusion out of the anterior chamber (AC), and a plate on the scleral side to prevent implant migration into the AC. The tip has multiple orifices for aqueous egress, with a $50 \mu \mathrm{m}$ lumen which offers some resistance to aqueous flow, and a notch in the back that helps direct aqueous flow posteriorly. Its distal tip penetrates into the $\mathrm{AC}$, while its proximal end is located under the scleral flap. The EX-PRESS glaucoma filtration device controls IOP by allowing a limited outflow of aqueous humor into the intrascleral space and thereafter into the subconjunctival space. The device is implanted underneath a partial thickness scleral flap through a needle sclerostomy, providing a more elegant and standardized sclerostomy than that of trabeculectomy. The EX-PRESS device-assisted guarded filtration procedure carries no risk of iris prolapse or bleeding from the ciliary body, unlike traditional trabeculectomy.

\section{CYPASS MICRO-STENT}

The CyPass is a micro-implantable polyimide device, $6 \mathrm{~mm}$ in length and a small lumen of $300 \mathrm{~mm}$, which is placed in the supraciliary and suprachoroidal space to increase uveoscleral outflow by creating a small cyclodialysis. It allows for an ab interno surgical approach, and is implanted in the suprachoroidal space through a clear corneal incision, leaving the trabecular meshwork intact. The distal end of the device penetrates into the suprachoroidal space, while the proximal collar remains in the anterior chamber, kept in place by three rings on its collar.
Initial anecdotal reports are hopeful of its efficacy; and combination CyPass and cataract surgery trial (COMPASS) and CyPass clinical evaluation trial (CYCLE) are non-randomized multi-center trials currently underway to assess the CyPass.

Another trial, 'DUETTE', is a European trial evaluating two different versions of the CyPass in a prospective and randomized study.

\section{CONCLUSION}

The quest for a more predictable and physiologic glaucoma procedure with rapid recovery and a greater margin of safety is ongoing. Even though encouraging results have been reported with non-penetrating glaucoma surgical procedures, it will take a while for glaucoma surgeons across the globe to adopt NPGS.

\section{REFERENCES}

1. Goldschmidt CR, Ticho U. Theoretical approach to laser trabeculotomy. Med Phys 1978 Mar-Apr;5(2):92-99.

2. Grant WM. Further studies on facility of flow through the trabecular meshwork. AMA Arch Ophthalmol 1958 Oct;60 (4 part I):523-533.

3. Krasnov MM. Q-switched laser goniopuncture. Arch Ophthalmol 1974 Jul;92(1):37-41.

4. Moller PM. Goniotomy and congenital glaucoma. Acta Ophthalmol (Copenh) 1977 Jun;55(3):436-442.

5. Tanihara H, Negi A, Akimoto M, Terauchi H, Okudaira A, Kozaki J, Takeuchi A, Nagata M. Surgical effects of trabeculotomy ab externo on adults eyes with primary open angle glaucoma and pseudoexfoliation syndrome. Arch Ophthalmol 1993 Dec;111(12):1653-1661.

6. Schwartz AL, Anderson DR. Trabecular surgery. Arch Ophthalmol 1974 Aug;92(2):134-138.

7. Grehn F. The value of trabeculotomy in glaucoma surgery. Curr Opinion Ophthalmol 1995 Apr;6(2):52-60.

8. Robin AL, Pollack IP. Q-switched neodymium-YAG laser angle surgery in open-angle glaucoma. Arch Ophthalmol 1985 Jun;103(6):793-795.

9. Grant WM. Experimental aqueous perfusion in enucleated human eyes. Arch Ophthalmol 1963 Jun;69:783-801.

10. Barkan O. Operation for congenital glaucoma. Am J Ophthalmol 1942;25(5):552-568.

11. Goel M, RG Picciani, Lee RK, Bhattacharya SK. Aqueous Humor Dynamics: A Review. Open Ophthalmol J 2010 Sep 3;4:52-59.

12. Van Buskirk, ME.; Harris, LM.; Wallace, P. Ito J. Clinical Atlas of Glaucoma. Philadelphia: WB Saunders; 1986.

13. Flocks M. The anatomy of the trabecular meshwork as seen in tangential section. AMA Arch Ophthalmol 1956 Nov;56(5):708-718.

14. Ashton N, Brini A, Smith R. Anatomical studies of the trabecular meshwork of the normal human eye. Br J Ophthalmol 1956 May;40(5):257-282.

15. Fine BS. Structure of the trabecular meshwork and the canal of Schlemm. Trans Am Acad Ophthalmol Otolaryngol 1966 Sep-Oct;70(5):777-790. 
16. Gong HY, Trinkaus-Randall V, Freddo TF. Ultrastructural immunocytochemical localization of elastin in normal human trabecular meshwork. Curr Eye Res 1989 Oct;8(10):1071-1082.

17. Fine BS. Observations on the drainage angle in man and rhesus monkey: a concept of the pathogenesis of chronic simple glaucoma: a light and electron microscopic study. Invest Ophthalmol 1964 Dec;3:609-646.

18. Ethier CR, Kamm RD, Palaszewski BA, Johnson MC, Richardson TM. Calculations of flow resistance in the juxtacanalicular meshwork. Invest Ophthalmol Vis Sci 1986 Dec; 27(12):1741-1750.

19. Johnson DH, Johnson M. Glaucoma Surgery and Aqueous Outflow. How does nonpenetrating glaucoma surgery work? Arch Ophthalmol 2002 Jan;120(1):67-70.

20. Johnson DH, Johnson M. How does nonpenetrating glaucoma surgery work? Aqueous outflow resistance and glaucoma surgery. J Glaucoma 2001 Feb;10(1):55-67.

21. Tripathi RC. Ultrastructure of Schlemm's canal in relation to aqueous outflow. Exp Eye Res 1968 Jul;7(3):335-341.

22. Ethier CR, Coloma FM, Sit AJ, Johnson M. Two pore types in the inner-wall endothelium of Schlemm's canal. Invest Ophthalmol Vis Sci 1998 Oct;39(11):2041-2048.

23. Bill A, Svedbergh B. Scanning electron microscopic studies of the trabecular meshwork and the canal of Schlemm: an attempt to localize the main resistance to outflow of aqueous humor in man. Acta Ophthalmol (Copenh) 1972;50(3):295-320.

24. Lee WR, Grierson L. Pressure effects on the endothelium of the trabecular wall of Schlemm's canal: a study by scanning electron microscopy. Albrecht Von Graefes Arch Klin Exp Ophthalmol 1975 Sep;196(3):255-265.

25. Johnstone MA, Grant WM. Pressure-dependent changes in structures of the aqueous outflow system of human and monkey eyes. Am J Ophthalmol 1973 Mar;75(3):365-383.

26. Johnson MC, Kamm RD. The role of Schlemm's canal in aqueous outflow from the human eye. Invest Ophthalmol Vis Sci 1983 Mar;24(3):320-325.

27. Hogan MJ, Alavarado JA, Weddell E. Cornea: the Limbus. In: Histology of the human eye: An atlas and textbook. Philadelphia: WB Saunders; 1971. p. 55-182.

28. Gong H, Tripathi RC, Tripathi BJ. Morphology of the aqueous outflow pathway. Microsc Res Tech 1996 Mar 1;33(4):336-367.

29. Nilsson SF. The uveoscleral outflow routes. Eye (Lond) 1997;11(Pt 2):149-154.

30. Kupfer C, Gaasterland D, Ross K. Studies of aqueous humor dynamics in man. II. Measurements in young normal subjects using acetazolamide and L-epinephrine. Invest Ophthalmol 1971 Jul;10(7):523-533.

31. Kupfer C, Ross K. Studies of aqueous humor dynamics in man. I. Measurements in young normal subjects. Invest Ophthalmol 1971 Jul;10(7):518-522.

32. Fautsch MP, Johnson DH. Aqueous Humor Outflow: What Do We Know? Where Will It Lead Us? Invest Ophthalmol Vis Sci 2006 Oct; 47(10):4181-4187.

33. Bill A. The Ocular Effects of Prostaglandins and Other eicosanoids. Prog Clin Biol Res 1989;312:417-427.

34. Johnson, M; Erickson, K. Mechanisms and routes of aqueous humor drainage. In: Albert DM, Jakobiec FA, editors. Principles and Practice of Ophthalmology. Vol. 4. Saunders; Philadelphia: 2000. pp. 2577-2595. Chapter 193B, Glaucoma.

35. Bill $\mathrm{A}$. The aqueous humor drainage mechanism in the cynomolgus monkey (Macaca irus) with evidence for unconventional routes. Invest Ophthalmol 1965 Oct;4(5):911-919.
36. Crawford K, Kaufman PL. Pilocarpine antagonizes prostaglandin F2 alpha-induced ocular hypotension in monkeys. Evidence for enhancement of uveoscleral outflow by prostaglandin F2 alpha. Arch Ophthalmol 1987 Aug;105(8): 1112-1116.

37. Gabelt BT, Kaufman PL. Prostaglandin F2 alpha increases uveoscleral outflow in the cynomolgus monkey. Exp Eye Res 1989 Sep;49(3):389-402.

38. Lutjen-Drecoll E, Tamm E. Morphological study of the anterior segment of cynomolgus monkey eyes following treatment with prostaglandin F2 alpha. Exp Eye Res 1988 Nov;47(5):761-769.

39. Bill A, Phillips CI. Uveoscleral drainage of aqueous humour in human eyes. Exp Eye Res 1971 Nov;12(3):275-281.

40. Alm A, Nilsson SF. Uveoscleral outflow-a review. Exp Eye Res 2009 Apr;88(4):760-768.

41. Bill A. The drainage of aqueous humor. Invest Ophthalmol 1975 Jan;14(1):1-3.

42. Maepea O, Bill A. The pressures in the episcleral veins, Schlemm's canal and trabecular meshwork in monkeys: effects of changes in intraocular pressure. Exp Eye Res 1989 Oct;49(4):645-663.

43. Maepea O, Bill A. Pressures in the juxtacanalicular tissue and Schlemm's canal in monkeys. Exp Eye Res 1992 Jun;54(6): 879-883.

44. Moses RA, Grodzki WJ, Etheridge EL, Wilson CD. Schlemm's canal: the effect of intraocular pressure. Invest Ophthalmol Vis Sci 1981 Jan;20(1):61-68.

45. Pederson JE, Gaasterland DE, MacLellan HM. Uveoscleral aqueous outflow in the rhesus monkey: importance of uveal reabsorption. Invest Ophthalmol Vis Sci 1977 Nov;16(11): 1008-1017.

46. Seiler T, Wollensak J. The resistance of the trabecular meshwork to aqueous humor outflow. Graefes Arch Clin Exp Ophthalmol 1985;223(2):88-91.

47. Rosenquist R, Epstein D, Melamed S, Johnson M, Grant WM. Outflow resistance of enucleated human eyes at two different perfusion pressures and different extents of trabeculotomy. Curr Eye Res 1989 Dec;8(12):1233-1240.

48. Lachkar $Y$, Hamard P. Nonpenetrating filtering surgery. Curr Opin Ophthalmol 2002 Apr;13(2):110-115.

49. Ethier CR, Kamm RD, Palaszewski BA, Johnson MC, Richardson TM. Calculations of flow resistance in the juxtacanalicular meshwork. Invest Ophthalmol Vis Sci 1986 Dec; 27(12):1741-1750.

50. Holmberg A. The fine structure of the inner wall of Schlemm's canal. AMA Arch Ophthalmol 1959 Dec;62(6):956-958.

51. Holmberg AS. Schlemm's canal and the trabecular meshwork: an electron microscopic study of the normal structure in man and monkey (Cercopithecus aethiops). Doc Ophthalmol 1965 Jan;19(1):339-373.

52. Inomata $\mathrm{H}$, Bill A, Smelser GK. Aqueous humor pathways through the trabecular meshwork and into Schlemm's canal in the cynomolgus monkey (Macaca irus): an electron microscopic study. Am J Ophthalmol 1972 May;73(5):760-789.

53. Tripathi RC. Mechanism of the aqueous outflow across the trabecular wall of Schlemm's canal. Exp Eye Res 1971 Jan;11(1):116-121.

54. Rhee DJ, Haddadin RI, Kang MH, Oh DJ. Matricellular proteins in the trabecular meshwork. Exp Eye Res 2009 Apr;88(4):694-703. 
55. Epstein DL, Freddo TF, Bassett-Chu S, Chung M, Karageuzian L. Influence of ethacrynic acid on outflow facility in the monkey and calf eye. Invest Ophthalmol Vis Sci 1987 Dec;28(12):2067-2075.

56. Epstein DL, Rohen JW. Morphology of the trabecular meshwork and inner wall endothelium after cationized ferritin perfusion in the monkey eye. Invest Ophthalmol Vis Sci 1991 Jan;32(1):160-171.

57. Schroeder A, Erickson-Lamy K, Epstein DL. Ethacrynic acid induced changes in cytoskeletal tubulin. Invest Ophthalmol Vis Sci 1989;30(3 Suppl):356.

58. Aihara M, Lindsey JD, Weinreb RN. Ocular hypertension in mice with a targeted type I collagen mutation. Invest Ophthalmol Vis Sci 2003 Apr;44(4):1581-1585.

59. Barany EH, Scotchbrook S. Influence of testicular hyaluronidase on the resistance to flow through the angle of the anterior chamber. Acta Physiol Scand 1954;30(2-3):240-248.

60. Barany EH, Woodin AM. Hyaluronic acid and hyaluronidase in the aqueous humour and the angle of the anterior chamber. Acta Physiol Scand 1955;33(2-3):257-290.

61. Bradley JM, Vranka J, Colvis CM, Conger DM, AlexanderJP, Fisk AS, Samples JR, Acott TS. Effect of matrix metalloproteinases activity on outflow in perfused human organ culture. Invest Ophthalmol Vis Sci 1998 Dec;39(13):2649-2658.

62. Gum GG, Samuelson DA, Gelatt KN. Effect of hyaluronidase on aqueous outflow resistance in normotensive and glaucomatous eyes of dogs. Am J Vet Res 1992 May;53:767-770.

63. Knepper PA, Farbman AI, Telser AG. Exogenous hyaluronidases and degradation of hyaluronic acid in the rabbit eye. Invest Ophthalmol Vis Sci 1984 Mar;25(3):286-293.

64. Pang IH, Fleenor DL, Hellberg PE, Stropki K, McCartney MD, Clark AF. Aqueous outflow-enhancing effect of tertbutylhydroquinone: involvement of AP-1 activation and MMP-3 expression. Invest Ophthalmol Vis Sci 2003 Aug;44(8): 3502-3510.

65. Anthony TL, Lindsey JD, Weinreb RN. Latanoprost's effects on TIMP-1 and TIMP-2 expression in human ciliary muscle cells. Invest Ophthalmol Vis Sci 2002 Dec;43(12):3705-3711.

66. El-Shabrawi Y, Eckhardt M, Berghold A, Faulborn J, Auboeck L, Mangge H, Ardjomand N. Synthesis pattern of matrix metalloproteinases (MMPs) and inhibitors (TIMPs) in human explant organ cultures after treatment with latanoprost and dexamethasone. Eye (Lond) 2000 Jun;14(Pt 3A):375-383.

67. Lindsey JD, Kashiwagi K, Boyle D, Kashiwagi F, Firestein GS, Weinreb RN. Prostaglandins increase proMMP-1 and proMMP-3 secretion by human ciliary smooth muscle cells. Curr Eye Res 1996 Aug;15(8):869-875.

68. Lutjen-Drecoll E, Wiendl H, Kaufman PL. Acute and chronic structural effects of pilocarpine on monkey outflow tissues. Trans Am Ophthalmol Soc 1998;96:171-191.

69. Nilsson SF. The uveoscleral outflow routes. Eye (Lond) 1997;11(Pt 2):149-154.

70. Crawford K, Kaufman PL. Pilocarpine antagonizes prostaglandin F2 alpha-induced ocular hypotension in monkeys. Evidence for enhancement of uveoscleral outflow by prostaglandin F2 alpha. Arch Ophthalmol 1987 Aug;105(8):1112-1116.

71. Toris CB, Zhan GL, Zhao J, Camras CB, Yablonski ME. Potential mechanism for the additivity of pilocarpine and latanoprost. Am J Ophthalmol 2001 Jun;131(6):722-728.

72. Barany EH. The mode of action of miotics on outflow resistance. A Study of pilocarpine in the vervet monkey Cercopithecus ethiops. Trans Ophthalmol Soc UK 1966;86:539-578.
73. Armaly MF. Studies on intraocular effects of the orbital parasympathetic pathway. III. Effect on steady-state dynamics. AMA Arch Ophthalmol 1959 Nov;62(5):817-827.

74. Armaly MF. Studies on intraocular effects of the orbital parasympathetics pathway. II. Effect on intraocular pressure. AMA Arch Ophthalmol 1959 Jul;62(1):117-124.

75. Armaly MF. Studies on intraocular effects of the orbital parasympathetic pathway. I. Technique and effects on morphology. AMA Arch Ophthalmol 1959 Jan;61(1):14-29.

76. Armaly MF, Burian HM. Changes in the tonogram during accommodation. AMA Arch Ophthalmol 1958 Jul;60(1): 60-69.

77. Barany E, Christensen RE. Cycloplegia and outflow resistance in normal human and monkey eyes and in primary openangle glaucoma. Arch Ophthalmol 1967 Jun;77(6):757-760.

78. Grierson I, Lee WR. Pressure-induced changes in the ultrastructure of the endothelium lining Schlemm's canal. Am J Ophthalmol 1975 Nov;80(5):863-884.

79. Grierson I, Lee WR. Junctions between the cells of the trabecular meshwork. Albrecht Von Graefes Arch Klin Exp Ophthalmol 1974;192(2):89-104.

80. Grierson I, Lee WR. The fine structure of the trabecular meshwork at graded levels of intraocular pressure. (1) Pressure effects within the near-physiological range (8-30 mm Hg). Exp Eye Res 1975 Jun;20(6):505-521.

81. Brubaker, RF. Measurement of aqueous flow by fluorophotometry. In: Ritch R, Shields MB, Krupin T, editors. The Glaucomas. St. Louis: Mosby; 1989. pp. 337-44.

82. Labbé A, Dupas B, Hamard P, Baudouin C. In Vivo Confocal Microscopy Study of Blebs after Filtering Surgery. Ophthalmology 2005 Nov;112(11):1979e1-1979e9.

83. Cairns JE. Trabeculectomy. Preliminary report of a new method. Am J Ophthalmol 1968 Oct;66(4):673-679.

84. Mills KB. Trabeculectomy: a retrospective long-term followup of 444 cases. Br J Ophthalmol 1981 Nov;65(11):790-795.

85. Picht G, Grehn F. Classification of filtering blebs in trabeculectomy: biomicroscopy and functionality. Curr Opin Ophthalmol 1998 Apr;9(2):2-8.

86. Picht G, Grehn F. Development of the filtering bleb after trabeculectomy. Classification, histopathology, wound healing process. Ophthalmologe 1998 May;95(5):W380-W387. (Ger).

87. Hamard P, Blondin C, Debbasch C, Warnet JM, Baudouin C, Brignole F. In vitro effects of preserved and unpreserved antiglaucoma drugs on apoptotic marker expression by human trabecular cells. Graefes Arch Clin Exp Ophthalmol 2003 Dec;241(12):1037-1043.

88. Alvarado J, Murphy C, Polansky J, Juster R. Age-related changes in trabecular meshwork cellularity. Invest Ophthalmol Vis Sci 1981 Nov;21(5):714-727.

89. Alvarado J, Murphy C, Juster R. Trabecular meshwork cellularity in primary open-angle glaucoma and nonglaucomatous normals. Ophthalmology 1984 Jun;91(6):564-579.

90. Grierson I. What is open angle glaucoma? Eye (Lond) 1987;1 (Pt 1):15-28.

91. Grierson I, Howes RC. Age related depletion of the cell population in the human trabecular meshwork. Eye (Lond) 1987;1(Pt 2):204-210.

92. Hamard P, Valtot F, Sourdille P, Bourles-Dagonet F, Baudouin C. Confocal microscopic examination of trabecular meshwork removed during ab externo trabeculectomy. Br J Ophthalmol 2002 Sep;86(9):1046-1052. 
93. Rohen JW, Lutjen-Drecoll E, Flugel C, Meyer M, Grierson I. Ultrastructure of the trabecular meshwork in untreated cases of primary open-angle glaucoma (POAG). Exp Eye Res 1993 Jun;56(6):683-692.

94. Johnson DH, Richardson TM, Epstein DL. Trabecular meshwork recovery after phagocytic challenge. Curr Eye Res 1989 Nov;8(11):1121-1130.

95. Zhou L, Fukuchi T, Kawa JE, Higginbotham EJ, Yue BY. Loss of cell-matrix cohesiveness after phagocytosis by trabecular meshwork cells. Invest Ophthalmol Vis Sci 1995 Apr;36(5): 787-795.

96. Zhou L, Li Y, Yue BY. Alteration of cytoskeletal structure, integrin distribution, and migratory activity by phagocytic challenge in cells from an ocular tissue-the trabecular meshwork. In Vitro Cell Dev Biol Anim 1999 Mar;35(3): 144-149.

97. Lütgen-Drecoll E, Rohen JW. Morphology of aqueous outflow pathways in normal and glaucomatous eyes. In: Ritch R, Shields MB, Krupin T, editors. The Glaucomas. Mosby-Year Book, Inc; St. Louis: 1996. pp. 89-124.

98. Potau JM, Canals M, Costa J, Merindano MD, Ruano D. Morphological alterations of the trabecular meshwork in primary open angle glaucoma. Arch Soc Esp Oftalmol 2000 Mar;75(3):159-164.

99. Lutjen-Drecoll E. Morphological changes in glaucomatous eyes and the role of TGF beta 2 for the pathogenesis of the disease. Exp Eye Res 2005 Jul;81(1):1-4.

100. Rohen JW, Futa R, Lütjen-Drecoll E. The fine structure of the cribriform meshwork in normal and glaucomatous eyes as seen in tangential sections. Invest Ophthalmol Vis Sci 1981 Oct;21(4):574-585.

101. Potau JM, Canals M, Costa J, Merindano MD, Ruano D. Morphological alterations of the trabecular meshwork in primary open angle glaucoma. Arch Soc Esp Oftalmol 2000 Mar;75(3):159-164.

102. Lutjen-Drecoll E. Morphological changes in glaucomatous eyes and the role of TGF-beta 2 for the pathogenesis of the disease. Exp Eye Res 2005 Jul;81(1):1-4.

103. Knepper PA, Goossens W, Palmberg PF. Glycosaminoglycan stratification of the juxtacanalicular tissue in normal and primary open-angle glaucoma. Investig Ophthalmol Vis Sci 1996 Nov;37(12):2414-2425.

104. Fautsch, Johnson DH. Aqueous Humor Outflow: What Do We Know? Where Will It Lead Us? Invest Ophthalmol Vis Sci 2006 Oct;47(10):4181-4187.

105. Knepper PA, Goossens W, Hvizd M, Palmberg PF. Glycosaminoglycans of the human trabecular meshwork in primary open-angle glaucoma. Invest Ophthalmol Vis Sci 1996 Jun;37(7):1360-1367.

106. Bhattacharya SK, Rockwood EJ, Smith SD, Bonilha VL, CrabbJS, Kuchtey RW, Robertson NG, Peachey NS, Morton CC, Crabb JW. Proteomics reveal Cochlin deposits associated with glaucomatous trabecular meshwork. J Biol Chem 2005 Feb;280(7):6080-6084.

107. Dan J, Belyea D, Gertner G, Leshem I, Lusky M, Miskin R. Plasminogen activator inhibitor-1 in the aqueous humor of patients with and without glaucoma. Arch Ophthalmol 2005 Feb;123(2):220-224.

108. Hu DN, Ritch R, Liebmann J, Liu Y, Cheng B, Hu MS. Vascular endothelial growth factor is increased in aqueous humor of glaucomatous eyes. J Glaucoma 2002 Oct;11(5):406-410.
109. Knepper PA, Mayanil CS, Goossens W, Wertz RD, Holgren C, Ritch R, Allingham RR. Aqueous humor in primary openangle glaucoma contains an increased level of CD44S. Invest Ophthalmol Vis Sci 2002 Janb;43(1):133-139.

110. Tripathi RC, Li J, Chan WF, Tripathi BJ. Aqueous humor in glaucomatous eyes contains an increased level of TGF-beta 2. Exp Eye Res 1994 Dec;59(6):723-727.

111. Tezel G, Kass MA, Kolker AE, Becker B, Wax MB. Plasma and aqueous humor endothelin levels in primary open-angle glaucoma. J Glaucoma 1997 Apr;6(2):83-89.

112. Gottanka J, Chan D, Eichhorn M, Lütjen-Drecoll E, Ethier CR. Effects of TGF-beta2 in perfused human eyes. Invest Ophthalmol Vis Sci 2004 Jan;45(1):153-158.

113. Brubaker RF. The effect of intraocular pressure on conventional outflow resistance in the enucleated human eye. Invest Ophthalmol 1975;14(4):286-292.

114. Smith R. A new technique for opening the canal of Schlemm. Preliminary Report. Br J Ophthalmol 1960 Jun;44(6):370-373.

115. Harms H, Dannheim R. Trabeculotomy-results and problems. Bibl Ophthalmol 1970;81:121-131.

116. Krasnov MM. Externalisation of Schlemm's canal (sinusotomy) in glaucoma. Br J Ophthalmol 1968 Feb;52(2):157-161.

117. Gillies WE. Trabeculotomy with fistulisation. A preliminary report of a modified trabeculotomy. Clin Exp Opthalmol 1976 Oct;4(3):152-154.

118. Cairns JE. Trabeculectomy. Preliminary report of a new method. Am J Ophthalmol 1968 Oct;66(4):673-679.

119. Rossier A, Uffer S, Mermoud A. Aqueous Dynamics in Experimental ab externo Trabeculectomy. Ophthalmic Res 2000 Jul-Aug;32(4):165-171.

120. McEwen WK. Application of Poiseuille's law to aqueous outflow. AMA Arch Ophthalmol 1958 Aug;60(2):290-294.

121. The AGFID project team. Experimental flow studies in glaucoma drainage device development. Br J Ophthalmol 2001 Oct;85(10):1231-1236.

122. Jacobi P, Dietlein T, Colling T, Krieglstein GK. Photoablative laser-grid trabeculectomy in glaucoma filtering surgery: histology and outflow facility measurements in porcine cadaver eyes. Ophthalmic Surg Lasers 2000 Jan-Feb;31(1):49-54.

123. Shaarawy T, Wu R, Mermoud A, Flammer J, Haefliger IO. Influence of non-penetrating glaucoma surgery on aqueous outflow facility in isolated porcine eyes. $\mathrm{Br} \mathrm{J}$ Ophthalmol 2004 Jul;88(7):950-952.

124. Minckler DS, Francis BA, Hodapp EA, Jampel HD, Lin SC, Samples JR, Smith SD, Singh K. Aqueous Shunts in Glaucoma. A Report by the American Academy of Ophthalmology. Ophthalmology 2008 Jun;115(6):1089-1098.

125. Minckler DS, Shammas A, Wilcox M, Ogden TE. Experimental studies of aqueous filtration using the Molteno implant. Trans Am Ophthalmol Soc 1987;85:368-392.

126. Prata JA Jr, Mermoud A, LaBree L, Minckler DS. In vitro and in vivo flow characteristics of glaucoma drainage implants. Ophthalmology 1995 Jun;102(6):894-904.

127. Lachkar $Y$, Hamard P. Nonpenetrating filtering surgery. Curr Opin Ophthalmol 2002 Apr;13(2):110-115.

128. Zimmerman TJ, Kooner KS, Ford VJ, Olander KW, Mandlekorn RM, Rawlings EF, Leader BJ, Koskan AJ. Trabeculectomy vs nonpenetrating trabeculectomy: a retrospective study of two procedures in phakic patients with glaucoma. Ophthalmic Surg 1984 Sep;15(9):734-739. 
129. Johnstone MA, Grant WM. Microsurgery of Schlemm's canal and the human aqueous outflow system. Am J Ophthalmol 1973 Dec;76(6):906-917.

130. Mermoud A. Sinusotomy and deep sclerectomy. Eye (Lond) 2000 Jun;14(Pt 3B):531-535.

131. Rossier A, Uffer S, Mermoud A. Aqueous dynamics in experimental ab externo trabeculectomy. Ophthalmic Res 2000 Jul-Aug;32(4):165-171.

132. Koslov VI, Bagrov SN, Anisimova SY, Osipov AV, Mogilevtsev VV. Nonpenetrating deep sclerectomy with collagen. Eye Microsurgery 1990;1:44-46.

133. Vaudaux J, Mermoud A. Aqueous humor dynamics in non-penetrating filtering surgery. Ophthalmol Pract 1998;38(4):S1064.

134. Sourdille P, Santiago PY, Villain F, Yamamichi M, Tahi H, Parel JM, Ducournau Y. Reticulated hyaluronic acid implant in nonperforating trabecular surgery. J Cataract Refract Surg 1999 Mar;25(3):332-339.

135. Demailly P, Lavat P, Kretz G, Jeanteur-Lunel MN. Nonpenetrating deep sclerectomy (NPDS) with or without collagen device (CD) in primary open-angle glaucoma: middle-term retrospective study. Int Ophthalmol 19961997;20(1-3):131-140.

136. Hamard P, Plaza L, Kopel, Quesnot S, Hamard H. Deep nonpenetrating sclerectomy and open-angle glaucoma. Intermediate results from the first operated patients. [Sclerectomie profonde non perforante (SPNP) et glaucome à angle ouvert. Résultats à moyen terme des premiers patients opérés. J Fr Ophtalmol 1999 Feb;22(1):25-31. (Fre).

137. Bechetoille A. External trabeculectomy with aspiration: surgical technique. J Fr Ophtalmol 1999 Aug-Sep;22(7):743-748. (Fre).

138. Hamard P, Sourdille P, Valtot F, Baudouin C. Evaluation of confocal microscope in the analysis of the external trabecular membrane during deep nonpenetrating sclerectomy. An. J Fr Ophtalmol 2001 Jan;24(1):29-35. (Fre).

139. Massy J, Gruber D, Muraine G, Brasseur G. Nonpenetrating deep sclerectomy in the surgical treatment of chronic openangle glaucoma: mid term results. J Fr Ophthalmol 1999 Apr; 22(3):292-298.

140. Dahan E, Drusedau MU. Nonpenetrating filtration surgery for glaucoma: control by surgery only. J Cataract Refract Surg 2000 May;26(5):695-701.

141. El Sayyad F, Helal M, El Kholify H, Khalil M, El-Maghraby A. Nonpenetrating deep sclerectomy versus trabeculectomy in bilateral open-angle glaucoma. Ophthalmology 2000 Sep; 107(9):1671-1674.

142. Stegmann R, Pienaar A, Miller D. Viscocanalostomy for openangle glaucoma in black African patients. J Cataract Refract Surg 1999 Mar;25(3):316-322.

143. Sanchez E, Schnyder CC, Sickenberg M, Chiou AGY, Hediguer SEA, Mermoud A. Deep sclerectomy: results with and without collagen implant. Int Ophthalmol 1997;20(1-3): 157-162.

144. Mermoud A, Schnyder CC. Nonpenetrating filtering surgery in glaucoma. Curr Opin Ophthalmol 2000 Apr;11(2):151-157.

145. Smit BA, Johnstone MA. Effects of viscocanalostomy on the histology of Schlemm's canal in primate eyes. Invest Ophthalmol Vis Sci 2000;41(4):S578.

146. Roters S, Lüke C, Jonescu-Cuypers CP, Engels BF, Jacobi PC, Konen W, Krieglstein GK. Ultrasound biomicroscopy and its value in predicting the long-term outcome of viscocanalostomy. Br J Ophthalmol 2002 Sep;86(9):997-1001.

147. Smit BA, Johnstone MA. Effects of viscoelastic injection into Schlemm's canal in primate and human eyes: potential relevance to viscocanalostomy. Ophthalmology 2002 Apr; 109(4):786-792.

148. Tamm ER, Carassa RG, Albert DM, Gabelt BT, Patel S, Rasmussen CA, Kaufman PL. Viscocanalostomy in rhesus monkeys. Arch Ophthalmol 2004 Dec;122(12):1826-1838.

149. Mandic Z, Saric D, Bojic L. Visco and phacoviscocanalostomy in managing glaucoma patients. Coll Antropol 2002 Dec;26 Suppl:165-169.

150. Mearza AA, Aslanides IM. Uses and complications of mitomycin C in ophthalmology. Expert Opin Drug Saf 2007 Jan;6(1):27-32.

151. Minckler DS, Baerveldt G, Alfaro MR, Francis BA. Clinical results with the Trabectome for treatment of open-angle glaucoma. Ophthalmology 2005 Jun;112(6):962-967.

152. Francis BA, See RF, Rao NA, Minckler DS, Baerveldt G. Ab interno trabeculectomy: development of a novel device (Trabectome) and surgery for open -angle glaucoma. J Glaucoma 2006 Feb;15(1):68-73.

153. Minckler D, Mosaed S, Dustin L, Ms BF. Trabectome Study Group. Trabectome (trabeculectomy-internal approach): additional experience and extended follow-up. Trans Am Ophthalmol Soc 2008;106:149-160.

154. Spiegel D, Wetzel W, Neuhann T, Stuermer J, Hoeh H, Garcia-Feijoo J, Martinez-De-La-Casa JM, Garcia-Sanchez J. Coexistent primary open-angle glaucoma and cataract: interim analysis of a trabecular micro-bypass stent and concurrent cataract surgery. Eur J Ophthalmol 2009 MayJun;19(3):393-399.

155. Spiegel D, García-Feijoó J, García-Sánchez J, Lamielle H. Coexistent primary open-angle glaucoma and cataract: preliminary analysis of treatment by cataract surgery and the iStent trabecular micro-bypass stent. Adv Ther 2008 May;25(5):453-464.

156. Zhou J, Smedley G. A trabecular bypass flow hypothesis. J Glaucoma 2005 Feb;14(1):74-83.

157. Mastropasqua L, Agnifili L, Ciancaglini M, Nubile M, Carpineto P, Fasanella V, Figus M, Lazzeri S, Nardi M. In vivo analysis of conjunctiva in gold micro shunt implantation for glaucoma. Br J Ophthalmol 2010 Dec;94(12):1592-1596. 